\title{
Prevalence of De-Quervain's tenosynovitis and its association with text messaging in collegiate girl students of Amritsar
}

\section{Vandana and Shyamal Koley}

\author{
Department of Physiotherapy, Guru Nanak Dev University, Amritsar - 143005, Punjab, India \\ *Corresponding author: Vandana; drvandana978@gmail.com
}

\begin{abstract}
Purpose: The purpose of the present study was to search the prevalence of De-Quervain's tenosynovitis in collegiate girl students of Amritsar and its association with mobile size and text messaging per day by the students.

Materials and methods: To fulfill the purpose, randomly selected 201 girl students those who used their smart phones of different sizes and for texting varied number of SMS every day, aged 18-26 years, were selected from Guru Nanak Dev University, Amritsar. The Visual Analogue Scale (VAS) was used to measure the pain in wrist. The Finkelstein test was conducted on the subjects to ascertain their De-Quervain's tenosynovitis status. Chi-square test was applied to search any association of De-Quervain's tenosynovitis and mobile size and SMS messaging by the students.
\end{abstract}

Results: It was observed that, out of 201 girl students, 20.89\% were reported Finkelstein test positive. Statistically, highly significant $(\mathrm{p}<0.001)$ association was found between positive Finkelstein status and the mobile size and SMS messaging per day by the collegiate girl students.

Conclusion: It might be concluded that $20.89 \%$ of the girl students had De-Quervain's tenosynovitis. Statistically highly significant association was found between positive Finkelstein status and the mobile size and SMS messaging per day by the collegiate girl students.

Keywords: De-Quervain's tenosynovitis; Visual Analogue Scale; Finkelstein test; collegiate girl students

\section{INTRODUCTION}

Fritz De-Quervain was the first in 1895, who defined De-Quervain's tenosynovitis as an inflammatory disease of the tendon of first dorsal compartment of the wrist. De-Quervain tenosynovitis is provoked by a stenosing tenosynovitis of thumb abductors around the radiostyloid process (Rossi, 2005). The prevalence of this condition is also increasing gradually with work-related conditions associated with long standing micro trauma (typing, computer work etc.) (Giovagnorio, 1997). It is due to repetitive and continued strain of the APL (Abductor Pollicis Longus) and EPB (Extensor Pollicis Brevis) tendons of thumb musculature as they pass under a thickened and swollen extensor retinaculum hence these activities which involved the repeated thumb pinching and wrist movement can be the consequence of this painful condition (Goel, 2015).

De-Quervain's tenosynovitis has numerous synonyms like blackberry thumb, smartphone thumb, texting tenosynovitis etc. (Ali, 2014). Mobile phone users were at high risk of developing various repetitive strain injuries (RSI) due to repetitive use of the phone in text messaging which result in musculoskeletal pain that may involve the muscles, nerves, tendons, ligaments, bones or joints (Eapen, 2014). The patients mainly complaint of pain and inflammation around radial styloid process and patients may also experience associated symptoms such as numbness, tingling, burning, and cramping (Goel, 2015).

The most standard test in De-Quervain's tenosynovitis is a positive Finkelstein's test (Wu, 2018). An acute trauma or an extreme, unaccustomed/new exercise are the definite aetiology of an acute trauma or an extreme, unaccustomed/new exercise (Ali, 2014). Thus, due to repetitive thumb and hand movement while using phone are early consideration of DeQuervain's tenosynovitis and previous studies also supported the fact that text messaging could be strongly related to DeQuervain's tenosynovitis (Ashurst, 2010; Eapen, 2014). The literature review revealed that the prevalence of de Quervain tenosynovitis was about $0.5 \%$ in men and $1.3 \%$ in women with peak prevalence between the ages of 20 and 40 (Satteson, 2021). Therefore, the prevalence of De-Quervain's tenosynovitis associated with SMS texting is sparse in this world.

Literatures related to the prevalence of De-Quervain's tenosynovitis in collegiate students and its association with text messaging is scanty. Thus, the present study was planned. 


\section{MATERIALS AND METHODS \\ SAMPLE}

A total of randomly selected 201 girl students aged 18-26 years were selected from the under- and post-graduate classes of Guru Nanak Dev University, Amritsar for the present study. The participants used their smart phones of different sizes texting varied number of SMS every day. Age of the subjects was registered from the records of their classes of the university. A self-structured questionnaire including information such as size of mobile phone used by the students for text, number of text messages per day, experiencing pain in the thumb/wrist, swelling or snapping sound over thumb and restriction or pain aggravation while handling different things, was applied to the subjects. Prior to the study, a written consent of the subjects was also taken. The study was approved by Institutional Ethical Committee.

\section{MEASUREMENT OF VISUAL ANALOGUE SCALE (VAS)}

The Visual Analogue Scale (VAS) was used to measure the pain in wrist. It is a validated method used widely for pain measurement.

\section{MEASUREMENT OF FINKELSTEIN TEST}

The patients were instructed to make a fist with the thumb enfolded inside the fingers. The researcher stabilized the forearm and passively deviated the wrist. Pain at the radial wrist, over the abductor pollicis longus and extensor pollicis brevis tendons was examined. A positive test indicated the De-Quervain's tenosynovitis.

\section{STATISTICAL ANALYYSIS}

Standard descriptive statistics (percentages) were analyzed for directly measured variables of the subjects using SPSS (Statistical Package for Social Science) version 20.0. Chi-square test was applied to search the association of different mobile sizes and number of text messaging per day with the De-Quervain's tenosynovitis. To indicate statistical significance, 5\% level of probability was used.

\section{RESULT}

TABLE 1 showed the association of Finkelstein status and size of mobile used by the collegiate girl students. The students with Finkelstein status +ve was reported maximum (47.61\%) with having the mobile size 5-6 inches, followed by $30.95 \%$ with having the mobile size $>6$ inches and the least (21.42\%) with having the mobile size $<5$ inches. On the other hand, the students with Finkelstein status -ve had the highest frequency $(44.15 \%)$ with the mobile size 5-6 inches, followed by $40.25 \%$ with the mobile size $>6$ inches and the least (15.48\%) with the mobile size $<5$ inches. However, the chi-square test $\left(\mathrm{X}^{2}=10.820\right)$ showed highly significant $(\mathrm{P}<0.0001)$ association between Finkelstein status and the mobile size.

TABLE 1: Association of Finkelstein status and size of mobile used by the collegiate students

\begin{tabular}{|c|c|c|c|c|}
\hline & $\begin{array}{c}<5 \text { inches } \\
\text { mobile size }\end{array}$ & $\begin{array}{l}5-6 \text { inches } \\
\text { mobile size }\end{array}$ & $\begin{array}{l}>6 \text { inches } \\
\text { Mobile size }\end{array}$ & TOTAL \\
\hline +Ve Finkelstein test & $9(21.43)$ & $20(47.62)$ & $13(30.95)$ & 42 \\
\hline -Ve Finkelstein test & $25(15.72)$ & $70(44.02)$ & $64(40.25)$ & 159 \\
\hline Total & 34 (16.91) & $90(44.77)$ & $77(38.31)$ & 201 \\
\hline
\end{tabular}

$\mathrm{X}^{2}=10.820$

The association of Finkelstein status with sms text messaging per day by the girl students was shown in Table 2 . The students with Finkelstein status +ve had the maximum frequency (57.50\%) SMS messaging $>100$ per day, followed by $42.50 \%$ with messaging $<100$ SMS per day. On the other hand, students with the Finkelstein status -ve had the maximum frequency $(76.39 \%)$ messaging $<100$ sms per day followed by $23.60 \%$ messaging $>100$ SMS per day. However, chi-square test $\left(X^{2}=17.414\right)$ showed highly significant $(p<0.0001)$ association between Finkelstein status and SMS messaging per day by the students studied.

TABLE 2: Association of Finkelstein status with SMS messaging per day by the students

\begin{tabular}{|c|c|c|c|}
\hline & $<100 \mathrm{sms} /$ day & $>100 \mathrm{sms} / \mathrm{day}$ & TOTAL \\
\hline +Ve Finkelstein test & 42.50 & 57.50 & 40 \\
\hline -Ve Finkelstein test & 76.39 & 23.60 & 161 \\
\hline Total & 140 & 61 & 201 \\
\hline
\end{tabular}

$\mathrm{X}^{2}=17.414$

\section{DISCUSSION}

Frequency of use and reliance on the smart-phone has been on the rise among young peer group. According to the recent data of market research institutions, about $48 \%$ of world population will use smart- phone by the end of 2021 and this percentage is expected to grow to $57 \%$ by 2024 . In India smart phone penetration rate data shows that by $2025,46 \%$ of mobile phone users would use a smart-phones, up from 33\% in 2021(Statista Research Department, 2021). 
As per market research reports, more than $80 \%$ of smart-phone owners in USA use their phones every day, and spend 2 hours 20 minutes daily on average (Analytics, 2021; Google, 2021). Specifically, a recent survey reports that the mobile device users spend more than 20 hours a week emailing, text messaging and using social network services, indicating their heavy reliance on smart - phones to connect and communicate with others (eMarketer, 2019).

In the present study, it was found that $20.89 \%$ of the studied girl students were Finkelstein status positive, i.e. had DeQuervain's tenosynovitis. Different size and weight of mobile phones were used by the subjects that might have produced varied results. Recent studies also revealed the prevalence of De-Quervain's tenosynovitis was more in females than males in ratio of 3:1 (Mak, 2018). Statistically highly significant $\left(X^{2}=10.820 ; p<0.0001\right)$ association were also found between Finkelstein status and the mobile size in the collegiate students studied (Table 1). (Baabdullah, 2020). Sustained and gripping and repetitive movements with the thumb and fingers have all been identified as risk factors which may lead to disorders of the thumb and thumb musculature in the forearm. The range of movement of the thumb varies according to the size of the mobile and orientation of the keys (Barakat, 2013).

The findings of the present study also showed that there was highly significant $\left(X^{2}=17.414 ; \mathrm{p}<0.0001\right)$ association between Finkelstein status and SMS messaging per day by the students studied (Table 2). It has been found that due to academic related activities the frequency of SMS texting increases tremendously among students related to healthcare profession which result in pain over the surface of radial aspect of the wrist and intensified by ulnar deviation of the hand. Hence there is positive correlation of thumb pain and sms texting. Overuse of smart-phones may cause pain weakness of thumb and wrist, neck pain and rigidity, increase prevalence of De-Quervain's tenosynovitis and smart-phones addiction disorders. In a cohort study it was found that females had a higher frequency of text messages daily. Hence the frequency was shown to correlate in a linear fashion with incidence of DQT. Therefore. The findings clearly showed the correlation of De-Quervain's tenosynovitis and text messaging. A recent study was also done among 300 students and it was observed that as the as the number of texts surpassed fifty per day, the incidence of a positive Finkelstein's test increased from $16.67 \%(<50$ text messages) to $67.2 \%$ (50-100 text messages), 89.7\% (100-200 text messages) and $72 \%$ (> 200 text messages). The study clearly showed the positive correlation between positive Finkelstein text status and text messaging per day. On the other hand, another study showed the decrement of percentage of Finkelstein test with increase in number of test messages, i.e. with $50 \%$ positive results for those texting 50 messages and $33 \%$ positive results among those going for 100 text messages per day. Therefore, the study showed no positive correlation between Finkelstein test and SMS texting (Lenhart et al., 2014). A positive correlation between Finkelstein test and SMS messaging was also reported by Ashurst (2010).

In the $21^{\text {st }}$ century, with the growing use of smart- phones especially among young population, concerns of musculoskeletal problems associated with the intensive use of smart-phone have also increased. A study showed that due to prolonged duration of mobile gaming result in incidence of $49 \%$ of De-Quervain's tenosynovitis among students. More frequent play, prolonged duration of mobile gaming, and change in wrist position were associated with higher risk of De-Quervain's tenosynovitis. The present study had few limitations. Firstly, only girl students from undergraduates and postgraduates were taken in this study. While texting, posture of sitting and thumb were also not noted from the subjects. Other activities like playing video games on mobile phones, typing on laptops details were not taken from the subjects. In sequence to hinder evolution of musculoskeletal disorder, a proper understanding of texting technique and connection to the muscle kinematic activity are needed. As De Quervain's tenosynovitis is a serious issue leading to dysfunction of the affected hand further researches should be done to know the prevalence of sms texting while using mobile phones.

\section{CONCLUSION}

The findings of the present study concluded that $20.89 \%$ of the girl students had De-Quervain's tenosynovitis. Statistically highly significant association was found between Finkelstein status and the mobile size in the collegiate girl students studied. Highly significant association was also reported between positive Finkelstein status and SMS messaging per day by the students.

\section{ACKNOWLEDGMENTS}

The authors are thankful to all the subjects for their cooperation in the study.

\section{CONFLICTS OF INTEREST}

There are no conflicts of interest.

\section{REFERENCES}

[1] A). Ali, M., Asim, M., Danish, S. H., Ahmad, F., Iqbal, A. and Hasan, S. D. (2014). Frequency of De Quervain's tenosynovitis and its association with SMS texting. Muscles, ligaments and tendons journal, 4(1): 74-78.

[2] B). Ashurst, J. V., Turco, D. A. and Lieb, B. E. (2010). Tenosynovitis caused by texting: an emerging disease. The Journal of the American Osteopathic Association, 110(5): 294-296.

[3] C). Baabdullah, A., Bokhary, D., Kabli, Y., Saggaf, O., Daiwali, M. and Hamdi, A. (2020). The association between smartphone addiction and thumb/wrist pain: A cross-sectional study. Medicine, 99(10): e19124. https://doi.org/10.1097/MD.0000000000019124

[4] D). Barakat, M. J., Field, J. and\& Taylor, J. (2013). The range of movement of the thumb. Hand (New York, N.Y.), 8(2): 179-182. https://doi.org/10.1007/s11552-013-9492-y

[5] E). Eapen, C., Kumar B.and Bhat A.K. (2010) Prevalence of cumulative trauma disorders in cell phone users. Journal of Musculoskeletal Research, 13 (3): 137-145. 
[6] F). Giovagnorio, F., Andreoli, C. and De-Cicco, M. L. (1997). Ultrasonographic evaluation of de Quervain disease. Journal of ultrasound in medicine: official journal of the American Institute of Ultrasound in Medicine, 16(10): 685-689. https://doi.org/10.7863/jum.1997.16.10.685

[7] G). Goel, R. and Abzug, J. M. (2015). De -Quervain's tenosynovitis: a review of the rehabilitative options. Hand (New York, N.Y.), 10(1): 1-5. https://doi.org/10.1007/s11552-014-9649-3

[8] H). Jenson, M. (2018). De Quervain's Tenosynovitis: Effective Diagnosis and Evidence-Based Treatment, Workrelated Musculoskeletal Disorders, Orhan Kohen, IntechOpen, DOI: 10.5772/intechopen.82029. Available from https://www.intechopen.com/books/work-related-musculoskeletal-disorders/de-quervain-s-tenosynovitiseffective-diagnosis-and-evidence-based-treatment

[9] I). Lenhart, A., Purcell, K., Smith, A. and Zickuhr, K. (2010). Social media \& mobile internet use among teens and young adults: Pew internet \& American life project Washington, DC.

[10] J). Rossi, C., Cellocco, P., Margaritondo, E., Bizzarri, F. and Costanzo, G. (2005). De Quervain disease in volleyball players. The American Journal of Sports Medicine, 33(3): 424-427

[11] K).Satteson, E. and Tannan, S. C. (2020). De-Quervain Tenosynovitis. In StatPearls. StatPearls Publishing.

[12] Wu, F., Rajpura, A. and Sandher, D. (2018). Finkelstein's Test Is Superior to Eichhoff's Test in the Investigation of de Quervain's Disease. Journal of Hand and Microsurgery, 10(2): 116-118. https://doi.org/10.1055/s-00381626690 